\title{
X-RAY DIFFRACTION MEASUREMENTS FOR RIVETED JOINTS. THE APPLICATION OF A NOVEL METHODOLOGY
}

\author{
Elżbieta Gadalińska \\ Jerzy Kaniowski \\ Institute of Aviation, Warsaw, Poland
}

\begin{abstract}
The X-ray diffraction method is the best, widely available, non-destructive measurement method used to determine the residual and load stresses in crystalline materials. This method can be applied without any limitations to flat specimens. Depending on the equipment geometry, the type of material and geometry of the specimen, there are many limitations, restrictions and recommendations which have to be fulfilled to obtain reliable results. This was the reason for working out a methodology for X-ray diffraction stress measurements for riveted specimens.

The first case to analyze is the necessity of choosing an X-ray tube suitable for the specimen material which will give the diffraction peaks in the range of $2 \Theta$ angles between $120^{\circ}$ and $180^{\circ}$. Afterwards it is crucial to make the best selection of Bragg's angle $2 \Theta$. In the vast majority of cases the best selection is the possibly biggest $2 \Theta$ angle because of the best accuracy of the measurement. However, for example for aluminum alloys (for $\mathrm{Cr}_{K_{\alpha}}$ radiation), this choice is not so obvious. It is much more convenient to perform measurements not for the highest diffraction angle. The best selection in this case is $2 \Theta=139,3^{\circ}$, and not $156,7^{\circ}$. Other selections which are necessary to be made before measurements are the collimator diameter, time of exposure, $\psi$ tilts and $\varphi$ oscillations. The proper selection of these parameters is crucial for the fast and efficient performing of measurements and for obtaining reliable results.

Before performing the measurement, especially in the case of the specimen with complicated geometry (for example in the case of riveted specimens made of aluminum alloys), it is necessary to analyze the results obtained paying special attention to the possibility of the appearing of the rivet head/driven rivet head shadow during the measurement. The work describes differences between the X-ray stress measurement results obtained without any interference and the results received after eliminating the selected diffraction peaks for which the shadow of rivet head/driven rivet head has appeared.
\end{abstract}

\section{THEORETICAL BASES OF THE MEASUREMENT}

The X-ray diffraction method is the only non-destructive method used for stress measurements. It enables measurement of absolute stress values.

The phenomenon of the X-ray diffraction is based on the interference of diffracted X radiation on the nodes of crystallographic lattice. The $\mathrm{X}$ radiation is a type of electromagnetic radiation whose wavelengths are between $5 \cdot 10^{-12} \mathrm{~m}$ and $10^{-8} \mathrm{~m}$. The $\mathrm{X}$ radiation is a result of collision of accelerated electrons with a metal target, the anode of the X-ray tube. The X-ray diffraction was originally observed by Max von Laue in 1912. Assuming that the X radiation is a type of the electromagnetic wave whose wavelength is of the same order as that of the interplanar spacing, 
von Laue prepared and performed an experiment whose aim was to proof that the $\mathrm{X}$ radiation diffracts on the nodes of the crystallographic lattice and after that it interferes if some special conditions are fulfilled. The mathematical formula which describes the phenomenon observed by von Laue was expressed for the first time by W.L. Bragg as follows:

$$
n \lambda=2 d_{h k l} \sin
$$

Where:

$n \quad-$ the whole number,

$\lambda \quad$ - wavelenght of $X$ radiation used in the experiment

$d_{h k l} \quad$ - interplanar spacing for planes indicated by Miller indices $h k l$

$\Theta \quad$ - the Bragg's angle; the angle between the incident beam of X radiation and the plane indicated by Miller indices $h k l$. The value of Bragg's angle is the condition of interference of diffracted X-ray beams.

The mechanism of X-ray diffraction on the nodes of the crystal lattice is showed in the Fig. 1.

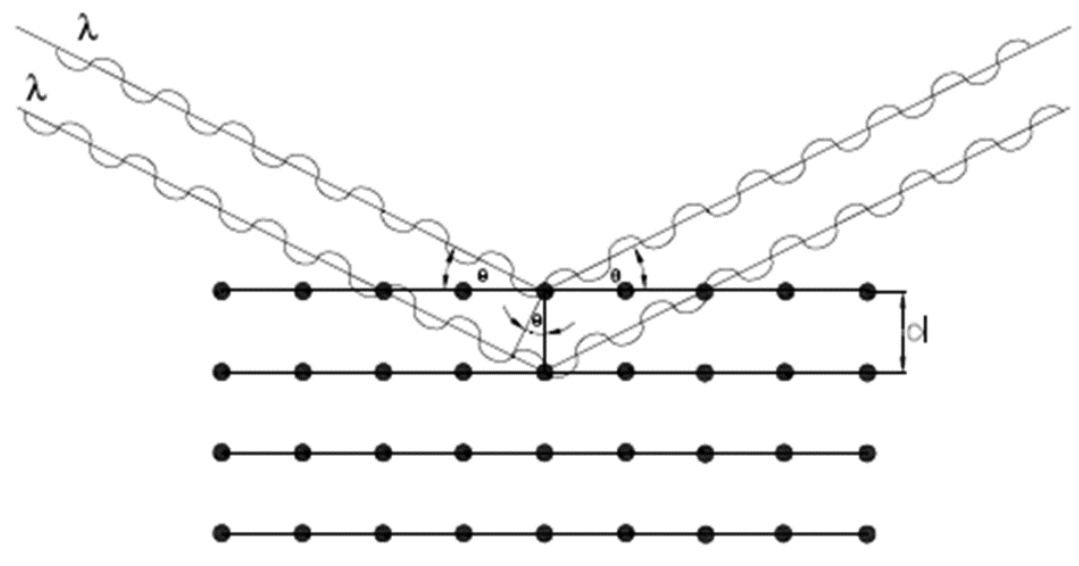

Fig. 1. X-ray diffraction on crystal lattice

Bragg's law permits obtaining information about interplanar spacing between planes indicated by Miller indices. Theoretically, if one knows the interplanar spacing for an unstressed specimen, it is possible to determine the strain or stress state. The practical equation which enables obtaining this information has the following form:

$$
\begin{aligned}
& \langle\varepsilon\rangle=\frac{1}{2} s_{2}\left[\left(\sigma_{11}-\sigma_{33}\right) \cos ^{2} \varphi+\left(\sigma_{22}-\sigma_{33}\right) \sin ^{2} \varphi+\sigma_{12} \sin 2 \varphi\right] \sin ^{2} \psi+s_{1}\left[\sigma_{11}+\sigma_{22}+\sigma_{33}\right]+ \\
& +\frac{1}{2} s_{2}\left[\left(\sigma_{13} \cos \varphi+\sigma_{23} \sin \varphi\right) \sin 2 \psi\right]
\end{aligned}
$$

where:

$\sigma_{11}, \sigma_{22}, \sigma_{33}, \sigma_{13}, \sigma_{23}-$ components of stress tensor,

$s_{1}, s_{2}$ - elastic constants,

$\psi \quad-$ angle between the normal to the surface of the specimen and the specimen surface.

$\varphi \quad-$ the angle which determines the direction in which the scattering vector is tilted during the measurement.

Approximating, this equation (2) gives the linear correspondence between the interplanar spacing and the $\sin ^{2} \psi$ (Fig. 2). The stress value in the determined direction is given by the slope of the line in the graph. 


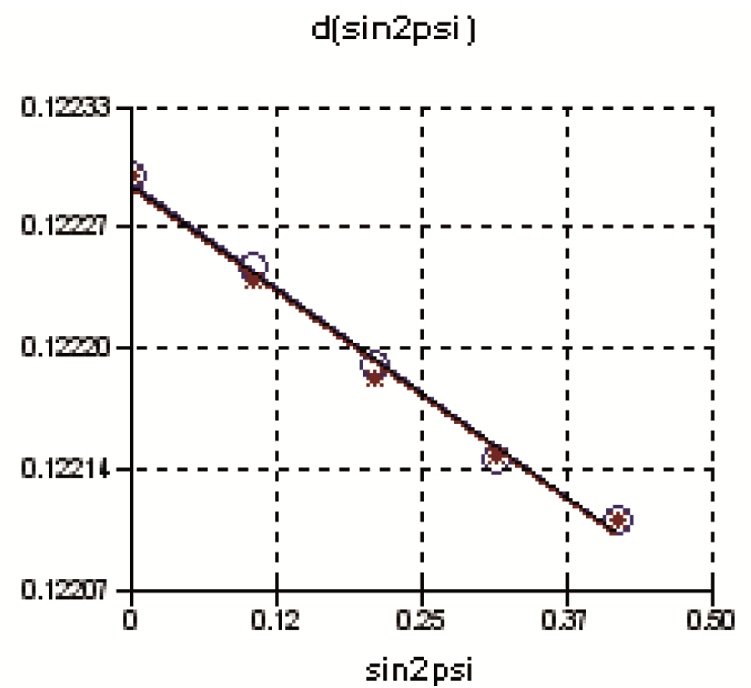

Fig. 2. Linear dependence between interplanar spacing of the crystal lattice and $\sin ^{2} \psi$

\section{MEASUREMENT METHODOLOGY}

Although the X-ray stress measurements method is well known, during the first test measurements on riveted samples many unexpected problems appeared which made the realization of these measurements impossible. It was necessary to work out a novel methodology to obtain the reliable information on the stress gradient around rivets. The methodological conclusions drawn are presented below alongside the presentation and comparison of the results obtained with and without this methodology.

\subsection{The influence of protective layers}

The first problem which should be solved in the case of the specimen made of the sheet of metal used in real constructions, was the non-homogenous cross-section problem. The aluminum sheets typically are covered with clad or/and anodizing layers to protect the core material from corrosion. Clad is the layer of pure aluminum and the anodizing layer is in fact the layer of aluminum oxide. The thickness of the clad layer is between $2 \%-6,5 \%$ of the thickness of the core material (in the case of $1,2 \mathrm{~mm}$ thick plates, the clad layer is $60 \mu \mathrm{m}$ thick). The anodizing layer is typically about $5-7 \mu \mathrm{m}$ thick, and the bold one is about $10 \mu \mathrm{m}$ thick. The conclusion is that clad is typically too thick to allow the residual stress measurement for specimens made of aluminum alloys so it is necessary to remove the clad layer at a given measurement point. The anodizing layer should not be so interruptive due to its almost insignificant thickness. It should be noted, however, that this layer will decrease the peaks intensity significantly. The diffraction peaks of aluminum oxide for $C r_{K_{\alpha}}$ radiation type should not be disturbing for the measurement.

\subsection{Selection of $2 \Theta$ angle}

The second problem to consider was the selection of the X-ray tube and the $2 \Theta$ angle for which the diffraction peak appears for $2 \Theta$ values greater than $125^{\circ}$.

The most suitable $\mathrm{X}$ radiation for measuring the residual stresses for the aluminium phase is the $K_{\alpha}$ radiation of the chromium tube: it gives diffraction peaks for two $2 \Theta$ angles $-139,3^{\circ}$ and $156,7^{\circ}$. It is very important to choose a relatively high value of $2 \Theta$ angle taking into consideration the precision of the measurement:

$$
\frac{\Delta d}{d}=-\Delta \theta \operatorname{ctg} \theta
$$


According to the above equation, at low $2 \Theta$ angles the value of $\Delta d$ is too small to be measured. At high $2 \Theta$ angles small changes in the lattice distances give measurable changes in $2 \Theta$. Generally, the highest diffraction angle value should be selected between $2 \Theta$ value $125^{\circ}$ and the $2 \Theta$ limit of the diffractometer.

As mentioned above, there are two diffraction peaks for $C r_{K_{\alpha}}$ radiation available while examining the aluminum phase of alloy: $139,3^{\circ}$ and $156,7^{\circ}$. Following the above reasoning, the $2 \Theta=156,7^{\circ}$ should be selected but there are some additional reasons which make the $2 \Theta=139,3^{\circ}$ a much more reasonable choice. Different crystallographic planes vary in their deformation mechanisms and give different responses in strain. Generally, measurements done on different planes are not comparable. If a sample has a large grain size or is textured, it is recommended to use a reflection $(2 \Theta$ angles) with the highest multiplicity instead of the highest possible $2 \Theta$ angle (Fig. 3). For other reflections the oscillation and the scatter in the $\sin ^{2} \psi$ graphs may increase (Fig. 4 and 5).

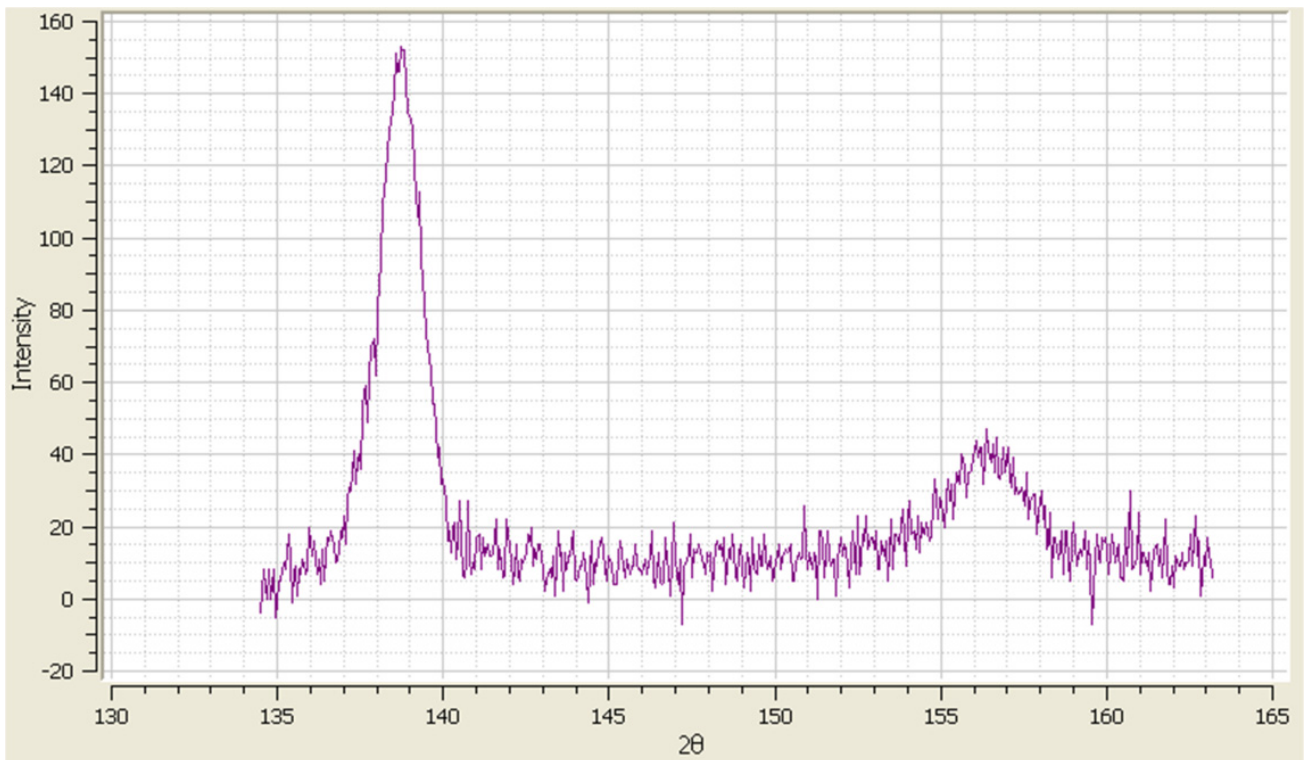

Fig. 3. Diffraction peaks measured on the riveted aluminium specimen.

This shows that the reflection from (311) plane at $2 \theta$ angle $139,3^{\circ}$ is stronger than the reflection from (222) plane at $2 \theta$ angle $156,7^{\circ}$

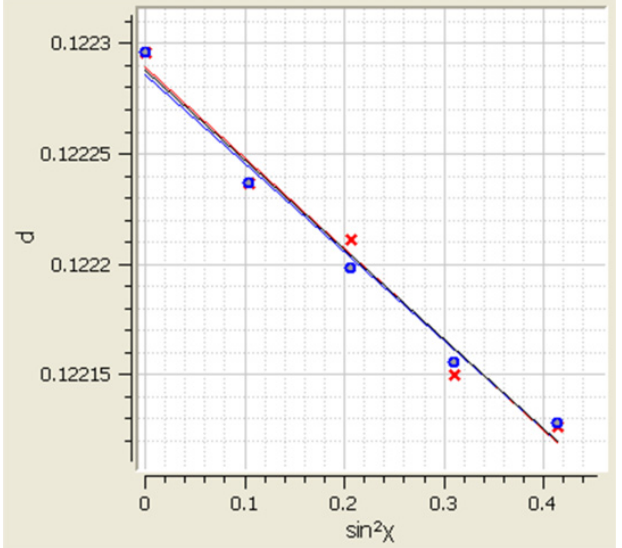

Fig. 4. X-ray diffraction stress measurement on riveted aluminium specimen for $2 \Theta$ angle $139,3^{\circ}(311)$

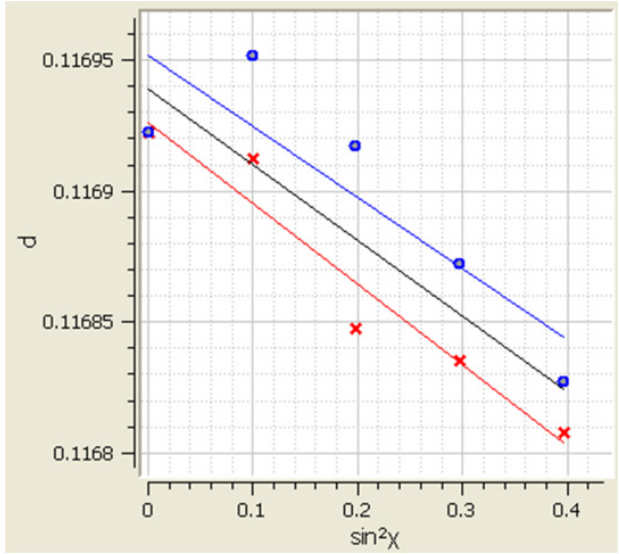

Fig. 5. X-ray diffraction stress measurement on riveted aluminium specimen for $2 \Theta$ angle $156,7^{\circ}(222)$ 


\subsection{Selection of collimator diameter}

The main aim of our research was to obtain as much information as possible on the stress distribution and its gradient around the rivet. The finite element method applied to this issue shows very large stress gradients both in the case of radial and tangential stresses [1,2]. This necessitates the application of collimators of very small diameters: 0,5 or $0,6 \mathrm{~mm}$.

\subsection{Selection of time of exposure}

The measurement of the stress gradient in aluminium alloys samples requires using collimators of very small diameters as it was indicated above. The time of exposure needed to obtain welldefined peaks is inversely proportional to the square of the collimator diameter. It is recommended to determine the optimal exposure time using increasing exposure time until no more improvements are obtained in the results. In the case of a textured sample or/and sample with a large grain size it would be helpful to use optimized $\varphi$ and $\psi$ oscillation options.

Additionally, to shorten the time of exposure the full power of the X-ray tube may be used, meaning voltage and current intensity of $30 \mathrm{kV}$ and $9 \mathrm{~mA}$ respectively. Another option is the exploitation of the long detectors instead of short ones. This option will reduce the exposure time by about $30 \%$. It was observed that the smallest collimator of $0,5 \mathrm{~mm}$ diameter did not give any reasonable results with short detectors. Only the exploitation of long detectors enables obtaining results for this collimator diameter.

The new Xtronic software used with the diffractometer makes it possible to introduce changes in the process of the measurement - the subtraction of the dark current can be done only once at the beginning of each measurement direction, which reduces exposure time by about $50 \%$.

\subsection{Selection of $\psi$ tilts and $\varphi$ oscillations}

Before the measurement it is necessary to define values of two angles of the goniometer position. They are $\psi$ angle, which is the angle between the perpendicular to the specimen surface and the incident beam, and $\varphi$ angle, which is the angle defining the direction in which the scattering vector is tilted.

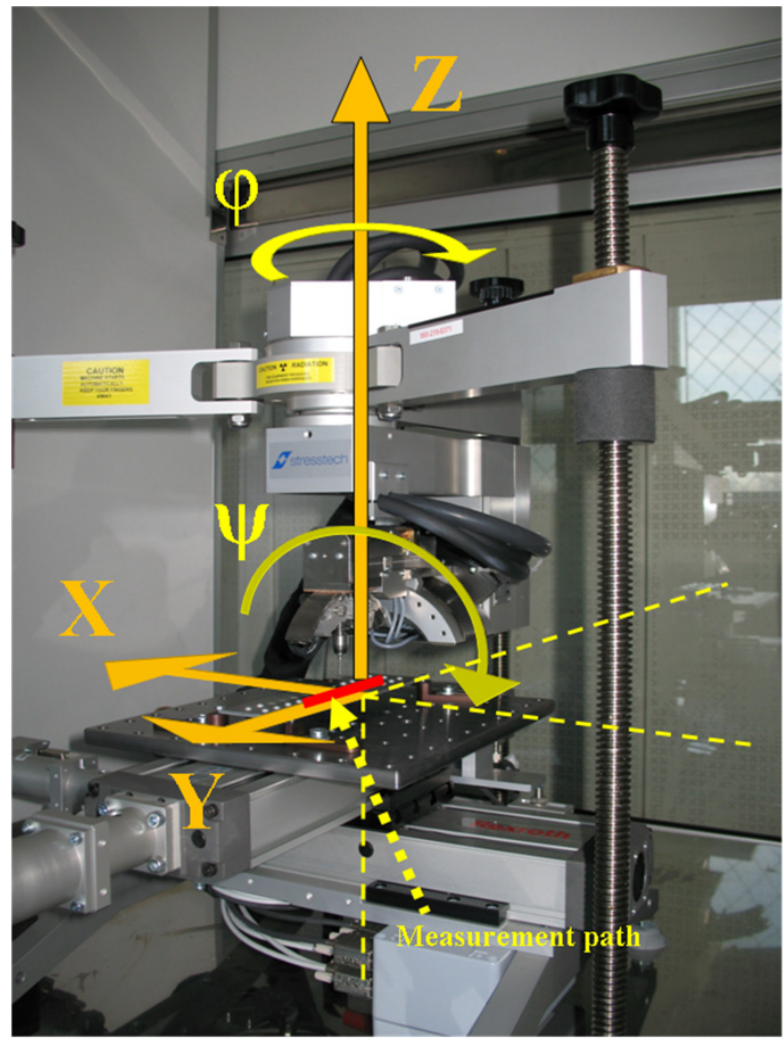


The minimum number of tilt angles $(\psi)$ during the measurement of the stress gradient is 4 on both negative and positive side, using tilt angles between $0^{\circ}-45^{\circ}$. It is reasonable to increase the tilt number and application of tilt angle oscillation in the case of textured samples - it might improve the stress results.

Oscillation of the $\varphi$ angle might improve stress results when textured and large grain sized samples are involved. Oscillations up to $\pm 5^{\circ}$ can be made without significantly affecting the accuracy of the stress in terms of measurement direction. It is not recommended to use oscillation higher than $\pm 10^{\circ}$. Increasing the number of the oscillation steps will improve the measurement and will also increase the total exposure time.

\subsection{Location of measurement points}

To shorten the time of measurement it is reasonable to estimate the stress distribution along the measurement path. It will enable to localize the measurement points in the way which optimizes the exposure time and will enable to measure stress values at the places where the stress gradient is more significant. It was necessary to perform the introductory short measurements to estimate stress values on the selected path. The procedure is that the same parameters can be used as in the standard measurement but in practice only $3 \psi$ values: $0,45^{\circ},-45^{\circ}$ are chosen. Although after this test measurement it was possible to select a lower number of points on the path, a closer study was performed. The method of introductory measurement was named a two tilt method.

The results of the two tilt method compared with the results of the measurement performed with a higher number of $\psi$ tilts are presented in Fig. 6.

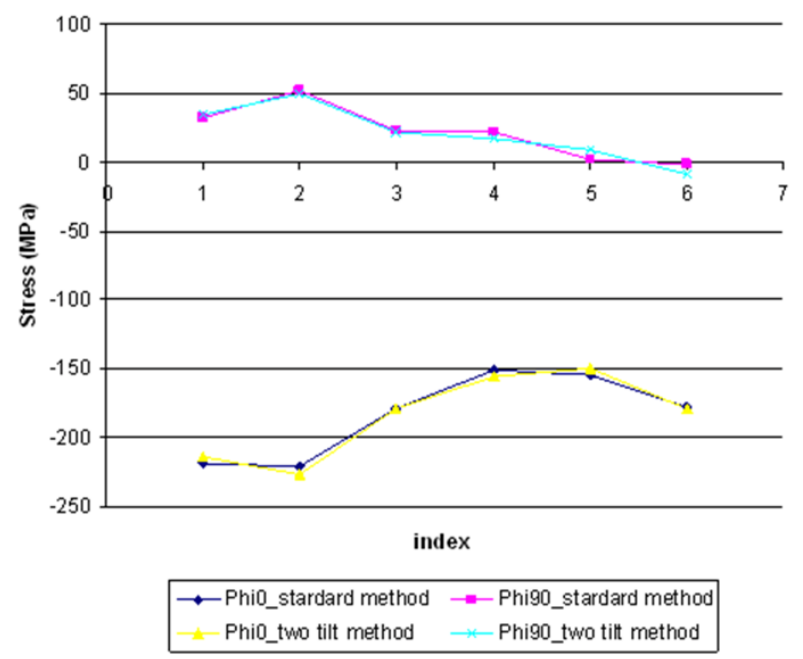

Fig. 6. Comparison between the results obtained with two tilt method and the standard method

\subsection{Shadow problem solution}

While performing the stress measurements of riveted samples with Stresstech equipment one should always bear in mind that for certain psi $\psi$ angles the X-ray beam could be disrupted by the manufactured rivet head or driven rivet head. Because of that, it is obligatory to make the geometrical analysis, which indicates $\psi$ tilts not acceptable due to the shadow problem. For measurement points in the intimate surroundings of the driven/manufactured rivet head during the tilt of about $\psi_{1}$ toward the driven/manufactured rivet head, the X-ray beam collides with the driven/manufactured rivet head and is unable to reach the measurement point. For measurement points in the intimate surroundings of the driven/manufactured head, geometrical analysis should reveal the above described collision. 
Mathematical relationship for boundary $\psi$ value for the manufactured rivet head and driven rivet head respectively are presented below (eq. 4 and 5):

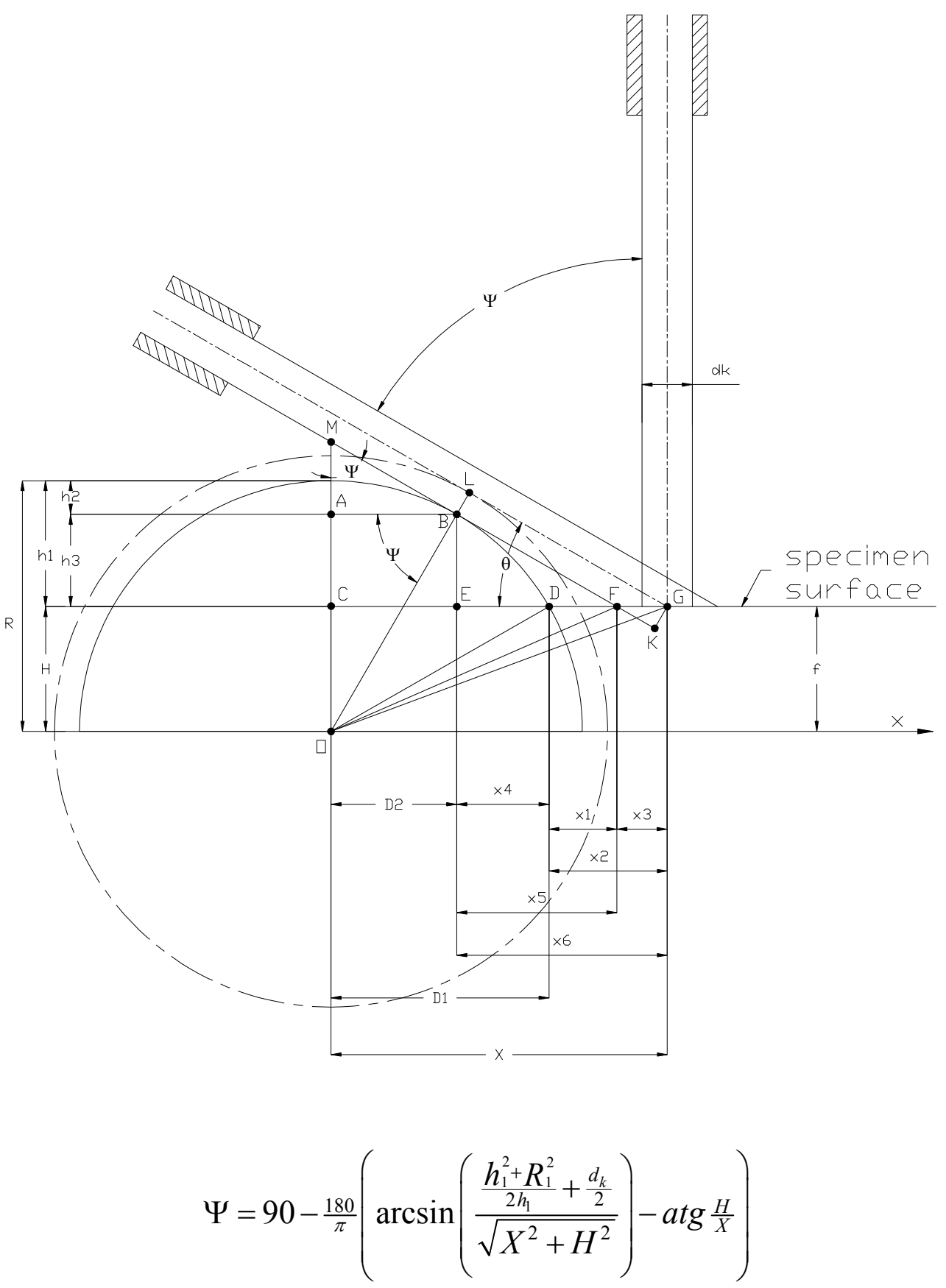

Where:

$h_{1}$ - manufactured rivet head height

$R_{1}$ - manufactured rivet head diameter

$d_{k}$ - inner collimator diameter

$X$ - distance between the collimator axis and the rivet axis

$H$ - difference between the manufactured rivet head radius and its height 


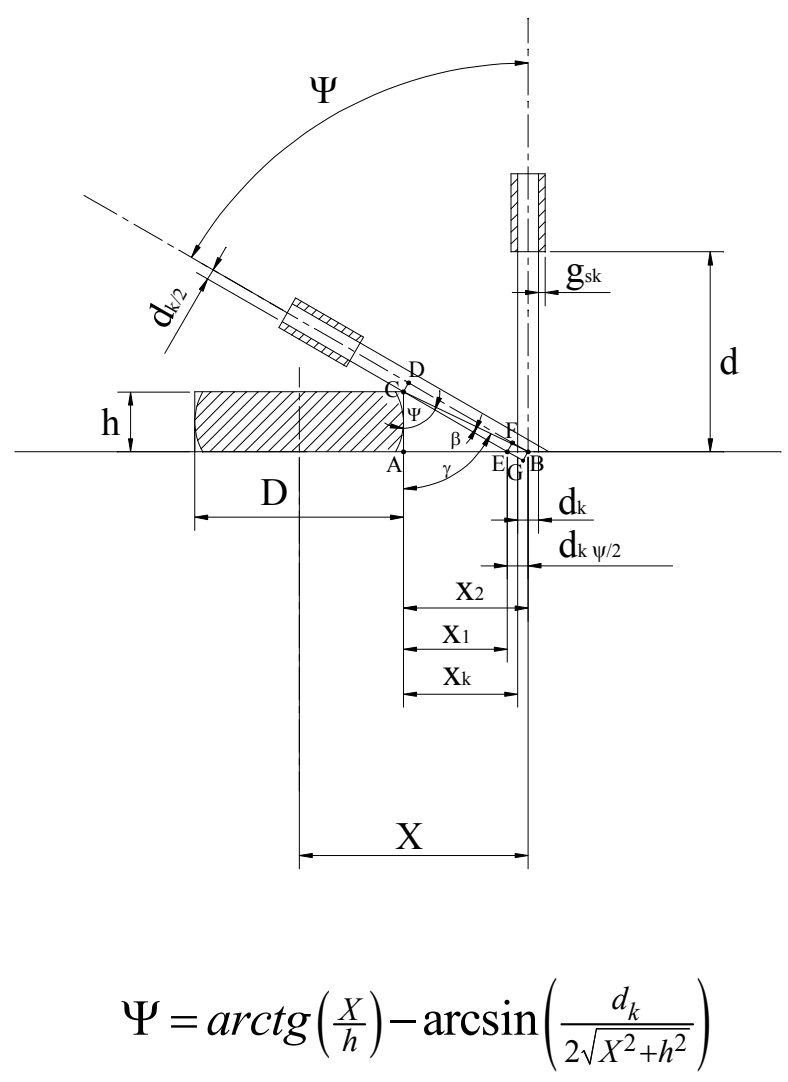

Where:

$X$ - distance between the collimator axis and the manufactured head brink

$h$ - formed rivet head height

$d_{k}$ - inner collimator diameter

The second, analogical problem for detectors is the driven/manufactured head shadow. Sometimes during tangential stresses measurements one detector may be shadowed by the driven/manufactured head. It is very important to analyse measurement results before stress calculations to determine if the detector covering occurred.

Another problem one needs to be aware of is the possibility of collision between the collimator and the driven/manufactured rivet head. It is crucial to determine the collision possibility before the measurement - otherwise the collision can result in the collimator's damage, which will disrupt any measurement for a few weeks.

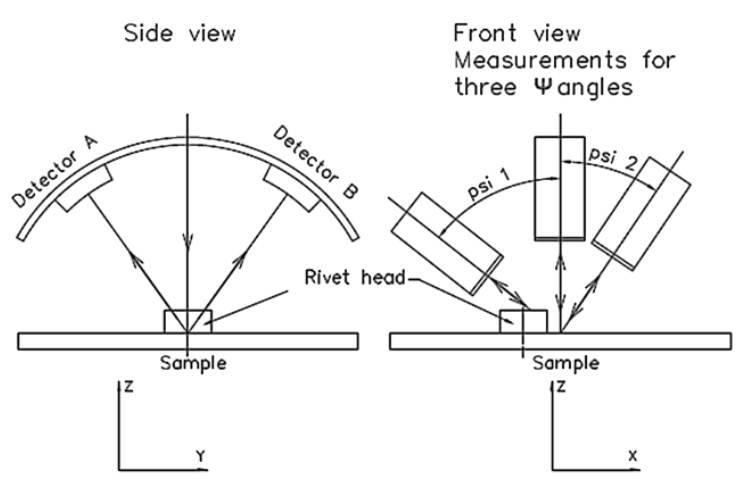

Fig. 7. Explanation of the driven rivet head shadow problem during $X$-ray stress measurement with Xstress3000 equipment

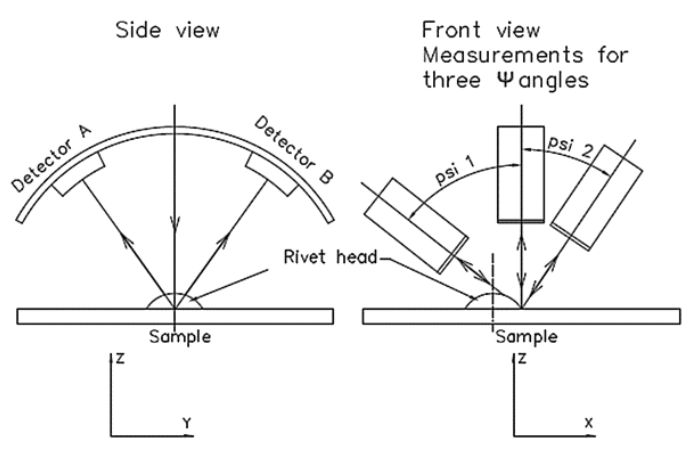

Fig. 8. Explanation of the manufactured rivet head shadow problem during $X$-ray stress measurement with Xstress3000 equipment 
For a calibrated distance from specimen $d$ at measurement points in the intimate surroundings of the driven/manufactured rivet head during the tilt of about $\psi_{1}$ (psi 1 ) toward the driven/manufactured rivet head, the collimator could touch the driven head/manufactured rivet head (fig. no. 7 and 8).

\section{THE APPLICATION OF THE NOVEL METHODOLOGY}

\subsection{The specimen, measurement paths and parameters}

The novel methodology described above was applied to the aluminum specimen presented in Fig. 9. The specimen during the measurement is presented in Fig. 10. The specimen was marked with No-4A-31 symbol.

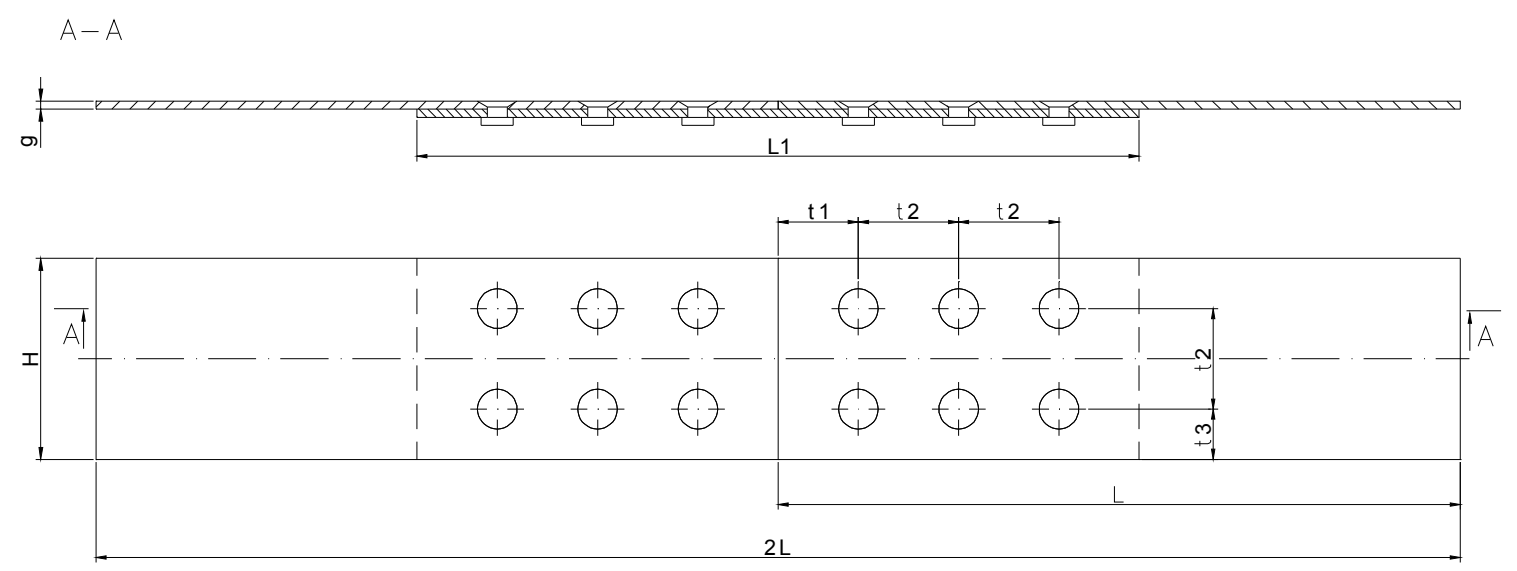

Fig. 9. The No-4A-31 specimen

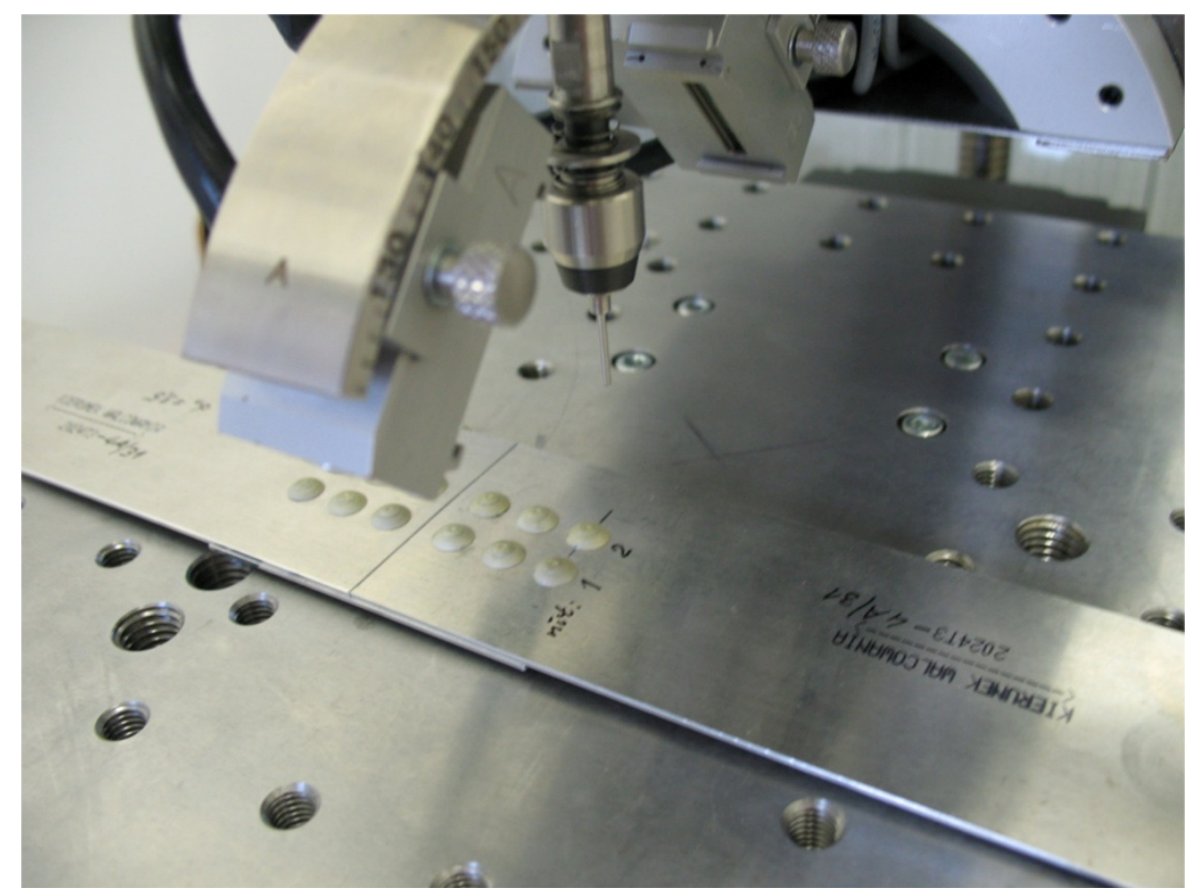

Fig. 10. The No-4A-31 specimen during the X-ray stress measurement

The material of the specimen was 2024-T3 alloy and the material of rivets was PA25 alloy. The specimen represents the riveted strap joint. Measurements were performed on both sides of the specimen along two paths: on the side of the manufactured rivet head (stress values were determined in radial direction only) and on the side of the driven rivet head (both, radial and 
tangential stresses values were obtained). In the case of the path between the rivets it was very important to take into account the manufactured/driven rivet head from both rivets simultaneously. Measurement paths were drawn on the specimen as it can be seen in Fig. 10. For each side of the specimen there were exploited measurement parameters as presented in the tab. 1 .

Table 1. Measurement parameters.

\begin{tabular}{|c|c|c|}
\hline 1. Data for calculation: & $\begin{array}{l}\text { 2theta } \\
\text { Background subtraction } \\
\text { Detectors } \\
\text { Peak limit } \\
\text { Peak shift } \\
\end{array}$ & $\begin{array}{l}\text { Calibrated } \\
\text { Linear } \\
\text { Both or only one } \\
\text { No } \\
\text { Cross corr. }\end{array}$ \\
\hline 2. Calibrated distance: & D & $4.37 \mathrm{~mm}$ \\
\hline 3. Material data: & $\begin{array}{l}\text { Material } \\
\text { Young module } \mathbf{E} \\
\text { Absorption coefficient } \boldsymbol{\mu} \\
\text { Poisson's ratio } \mathbf{v}\end{array}$ & $\begin{array}{l}\mathrm{Al} 139,3^{\circ} \\
70600 \mathrm{MPa} \\
42.71 / \mathrm{mm} \\
0.345\end{array}$ \\
\hline $\begin{array}{l}\text { 4. Measurement } \\
\text { parameters: }\end{array}$ & $\begin{array}{l}2 \Theta / \mathrm{hkl} \\
\text { Exposure time } \\
\text { Method of measurement } \\
\Phi \text { angles } \\
\boldsymbol{\Phi} \text { oscillations } \\
\text { Angles of boundary } \Psi, \\
\text { Angles and oscillations number of } \Psi \\
\text { Radiation }\end{array}$ & $\begin{array}{l}139,3^{\circ} / 311 \\
50 \mathrm{~s} \\
\text { Psi } \\
0 ; 90^{\circ} ;-90^{\circ} \\
10^{\circ} / 5 \\
-39^{\circ} /+39^{\circ} \\
\pm 6^{\circ} ; 5 / 5 \\
\mathrm{CrK}_{\alpha}\end{array}$ \\
\hline 5. Collimator: & Diameter & $0,8 \mathrm{~mm}$ \\
\hline
\end{tabular}

\footnotetext{
${ }^{1}$ depending on the solution to the manufactured/driver rivet head shadow problem
}

The measurements results are presented below in graphs $1-6$.

\subsection{Measurement results - the manufactured rivet head}
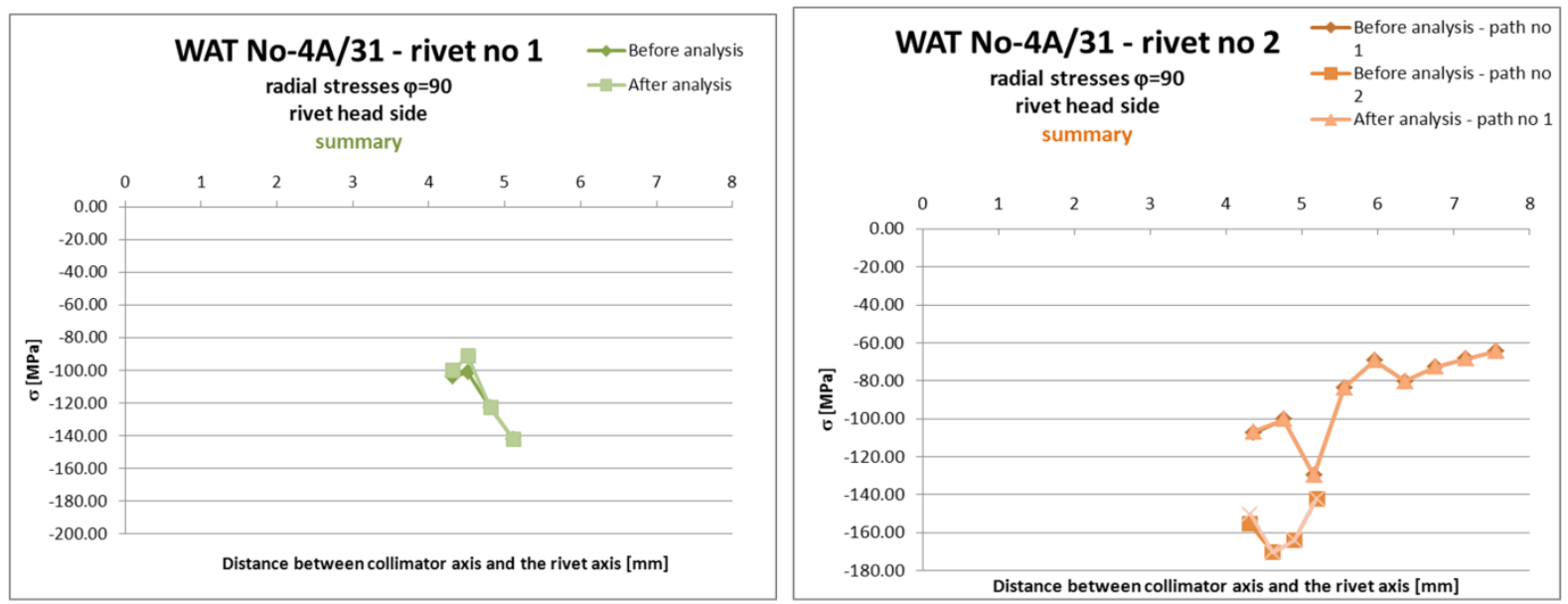

Graph 1. Rivets no. 1 and 2, radial direction. Comparison results obtained before and after rivet head shadow analysis 


\subsection{Measurement results - the manufactured rivet head}
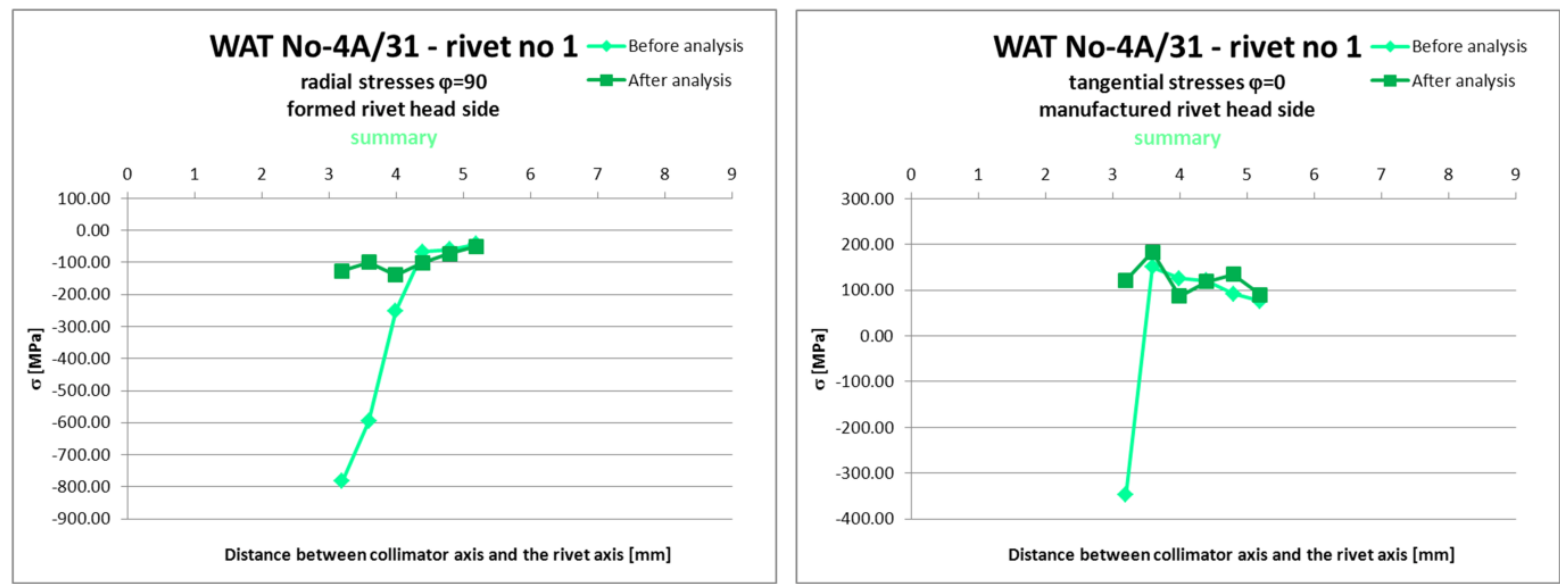

Graph 2. Rivet no. 1, radial and tangential direction. Comparison of the results obtained before and after the manufactured rivet head shadow analysis
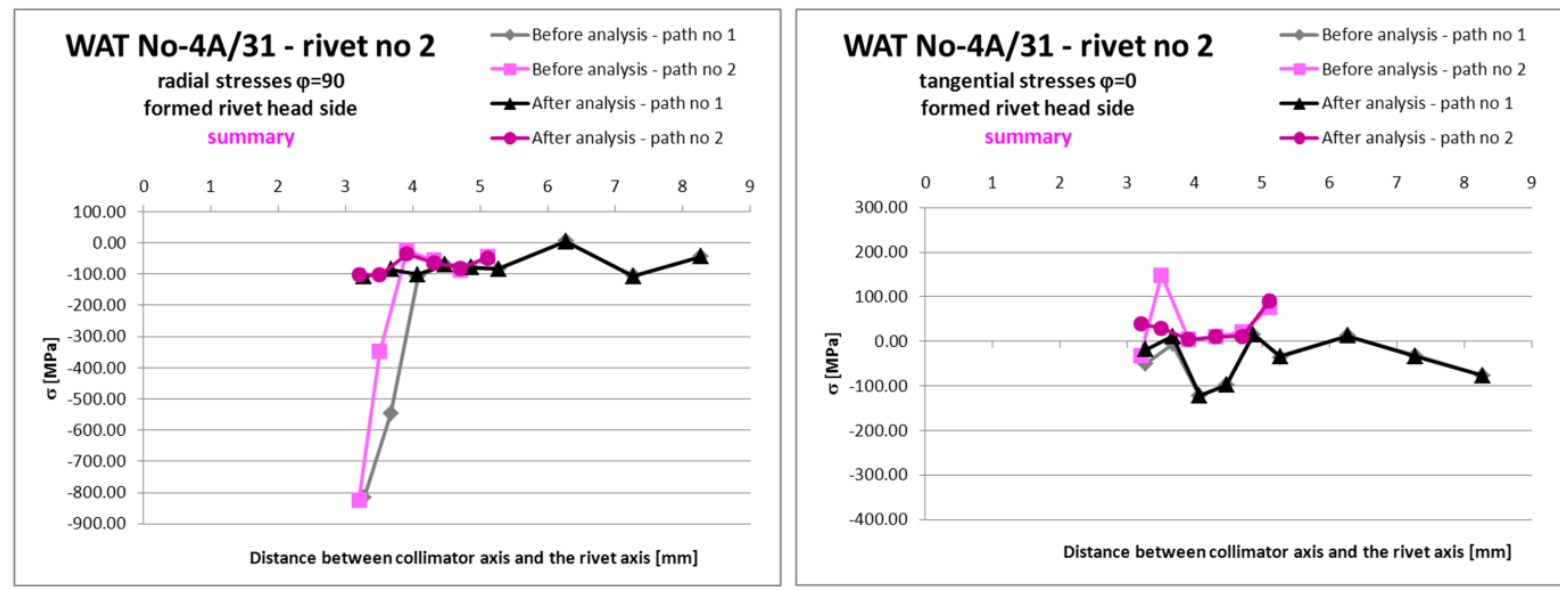

Graph 3. Rivet no. 2, radial and tangential direction. Comparison of the results obtained before and after the manufactured rivet head shadow analysis

\section{CONCLUSIONS}

The measurements programme performed under the Eureka! IMPERJA project was concluded with the following observations:

- a well-rounded methodology is necessary to perform reliable and effective X-ray stress measurements; such a methodology was presented in this paper,

- stress values in two directions (radial and tangential), in the riveted specimen, were obtained during the work - the obtained values are good introduction to stricter stress gradient measurements,

- it can be seen that stress measurements on the side of the driven rivet head are much more complicated than those on the side of the manufactured rivet head because of the shadow problem - careful analysis is necessary to introduce suitable corrections. 


\section{REFERENCES}

[1] Kaniowski J. (2010). Improving the Fatigue Performance of Riveted Joints in Airframes. Warsaw: Institute of Aviation. (research project report Nr EUREKA/59/2006).

[2] Müller R.P.G. (1995) An experimental an Analytical Investigation on the Fatigue Behaviour of Fuselage Riveted Lap Joints, Ph. D. Thesis, Delft University of Technology, The Netherlands, Delft.

[3] Kaniowski J., Korzeniewski B., Hakanen M. (2011). Methodology of residual stress measurements for rivet joints, Fatigue of Aircraft Structures, Vol. 1 (2011) 42-52, DOI: 10.2478/v10164-010-0036-4 